\title{
Parametric Study of R.C.C Voided and Solid Flat Plate Slab using SAP 2000
}

\author{
SaifeeBhagat ${ }^{1}$,Dr. K. B. Parikh ${ }^{2}$ \\ ${ }^{\text {I}}$ (Applied Mechanics Department, Government Engineering College,Dahod (Gujarat ), India.) \\ ${ }^{2}$ (Applied Mechanics Department, Government Engineering College,Dahod (Gujarat), India.)
}

\begin{abstract}
The use of flat plate slab is gaining much popularity amongst architects, because the flat plate slab system provides a way for the architect to achieve the concept of high and completely flat ceiling with no beam. As we know that, slab is one of the largest members consuming concrete, when the load acting on the slab is large or clear span between columns is more, the slab thickness is on increasing. It leads to consume more material such as concrete and steel, due to that self-weight of slab is increase. To avoid these disadvantages various studies carried out and researchers suggest voided flat plate slab system to reduce the self-weight of the slab. In this paper various parameters of the voided and solid flat plate slabs is calculated to compare the both systems. To evaluate the performance of the R.C.C voided and solid flat plate slabs, modelling of slabs is carried out using SAP 2000 having span ranging from $6 x 6 \mathrm{~m}$ to $14 x 14 \mathrm{~m}$ of $4 \times 4$ bay in both direction with thickness of the slabs 280 to $600 \mathrm{~mm}$. The results drawn from the SAP 2000 are Reaction, Deflection, Moment and Reinforcement required for the voided and solid flat plate slabs.
\end{abstract}

Key words; R.C.C Voided flat plate slab, R.C.C solid flat plate slab, SAP 2000, Reaction, Deflection, Moment, Reinforcement.

\section{Introduction}

The flat plate floor systems are commonly used in multi-storey buildings, because flat plate floor system present advantages from technical and functional point of view. The self-weight of slab can reduce by replacing the middle height of the cross section of slab with void former. Here, to carry out the parametric study of voided flat plate slabs, different size of hollow void former ( 180 to $450 \mathrm{~mm}$ ) is consider for various cases of slab thickness ( 280 to $600 \mathrm{~mm}$ ). The modelling of voided flat plate slabs is carry out same as traditional flat plate slabs by applying the stiffness multiplication factor and modified self-weight of the voided flat plate slabs. The stiffness multiplication factor can be derived from the calculation of second moment of inertia of voided slab and solid slab.The other necessary checks are also done to prove that the voided slab can de model as solid flat slabs with necessary adjustment in certain parameters. The SAP 2000 results show that the behaviour of the voided flat plate slabs is almost same as that of solid voided flat slab in same condition.

\section{Reaction}

The main purpose of to carry out results for reaction is to confirm that the methodology that was adopted to perform the study of voided and solid flat slab is acceptable or not. It means that applied stiffness multiplication factor and modified self-weight of the voided slabs are correct or not. To perform the study, for different cases of voided and solid flat slabs are model in SAP 2000 ranging from $6 \times 6 \mathrm{~m}$ to $14 \times 14 \mathrm{~m}$ having thickness $280 \mathrm{~mm}$ to $600 \mathrm{~mm}$ with spherical ball diameter $180 \mathrm{~mm}$ to $450 \mathrm{~mm}$ respectively and slabs having 4 bays in both direction. For the punching shear criteria, the portion around the column is designed as the solid flat slabs without hollow void former. The results are taken at the centre of the slab considering only gravitational load.To validate the results of Reaction taken from SAP 2000 for voided flat slab, the numerical calculation is carry out of voided slab and the results are shown in Table -1. The Comparative results of reaction for voided and solid Flat slabs are shown in Table -2. The results have revealed that reaction of solid flat slab is higher than that of voided flat slab because of higher self-weight. Moreover, the values of reaction taken from SAP 2000 and by numerical calculation of interior bay are same for voided flat slab. From results it may be conclude that the methodology, which adopted to get the results are acceptable.

Table -1 Result for validation of Reaction

\begin{tabular}{|c|c|c|c|c|}
\hline \multirow{2}{*}{ Slab Thk $(\mathrm{mm})$} & \multirow{2}{*}{ Ball Diameter $(\mathrm{mm})$} & \multirow{2}{*}{ Span $(\mathrm{m})$} & \multicolumn{2}{|c|}{ Reaction $(\mathrm{KN})$} \\
\cline { 3 - 5 } & & & Voided Slab & Numerical Calculation \\
\hline \multirow{2}{*}{280} & \multirow{2}{*}{180} & $6 \times 6$ & 194.76 & 194.39 \\
\cline { 3 - 5 } & & $7 \times 7$ & 354.89 & 265.6 \\
\cline { 3 - 5 } & \multirow{2}{*}{225} & $6 \times 6$ & 215.02 & 217.06 \\
\cline { 3 - 5 } & & $7 \times 7$ & 292.97 & 297.42 \\
\hline
\end{tabular}


Parametric Study of R.C.C Voided and Solid Flat Plate Slab using SAP 2000

\begin{tabular}{|c|c|c|c|c|}
\hline & & $8 \times 8$ & 397.02 & 395.96 \\
\hline \multirow{2}{*}{370} & \multirow{2}{*}{270} & $8 \times 8$ & 425.95 & 425.12 \\
\hline & & $9 \times 9$ & 535.48 & 543.54 \\
\hline \multirow{2}{*}{420} & \multirow{2}{*}{315} & $9 \times 9$ & 593.64 & 607.73 \\
\hline & & $10 \times 10$ & 746.67 & 758.61 \\
\hline \multirow{2}{*}{470} & \multirow{2}{*}{360} & $10 \times 10$ & 808.29 & 826.52 \\
\hline & & $11 \times 11$ & 988.12 & 1012 \\
\hline \multirow{2}{*}{520} & \multirow{2}{*}{405} & $11 \times 11$ & 1077.33 & 1109.99 \\
\hline & & $12 \times 12$ & 1284.84 & 1336.08 \\
\hline \multirow{2}{*}{600} & \multirow{2}{*}{450} & $13 \times 13$ & 1739.35 & 1823.7 \\
\hline & & $14 \times 14$ & 2041.78 & 2140.82 \\
\hline
\end{tabular}

Table -2 Result of Reaction for voided and solid flat slab

\begin{tabular}{|c|c|c|c|c|}
\hline \multirow{2}{*}{ Slab Thk (mm) } & \multirow{2}{*}{ Ball Diameter (mm) } & \multirow{2}{*}{ Span (m) } & \multicolumn{2}{|c|}{ Reaction $(\mathrm{KN})$} \\
\hline & & & Voided Slab (KN) & Solid Slab (KN) \\
\hline \multirow{3}{*}{280} & \multirow{3}{*}{180} & $6 \times 6$ & 194.76 & 237.67 \\
\hline & & $7 \times 7$ & 264.89 & 323.02 \\
\hline & & $8 \times 8$ & 355.15 & 421.9 \\
\hline \multirow{3}{*}{330} & \multirow{3}{*}{225} & $6 \times 6$ & 215.02 & 279.7 \\
\hline & & $7 \times 7$ & 292.97 & 380.7 \\
\hline & & $8 \times 8$ & 397.02 & 497.24 \\
\hline \multirow{2}{*}{370} & \multirow{2}{*}{270} & $8 \times 8$ & 425.95 & 557.52 \\
\hline & & $9 \times 9$ & 535.48 & 705.61 \\
\hline \multirow{2}{*}{420} & \multirow{2}{*}{315} & $9 \mathrm{x} 9$ & 593.64 & 784.95 \\
\hline & & $10 \times 10$ & 746.67 & 988.84 \\
\hline \multirow{2}{*}{470} & \multirow{2}{*}{360} & $10 \times 10$ & 808.29 & 1106.56 \\
\hline & & $11 \times 11$ & 988.12 & 1338.94 \\
\hline \multirow{2}{*}{520} & \multirow{2}{*}{405} & $11 \times 11$ & 1077.33 & 1481.38 \\
\hline & & $12 \times 12$ & 1284.84 & 1762.97 \\
\hline \multirow{2}{*}{600} & \multirow{2}{*}{450} & $13 \times 13$ & 1739.35 & 2387.36 \\
\hline & & $14 \times 14$ & 2041.78 & 2668.95 \\
\hline
\end{tabular}

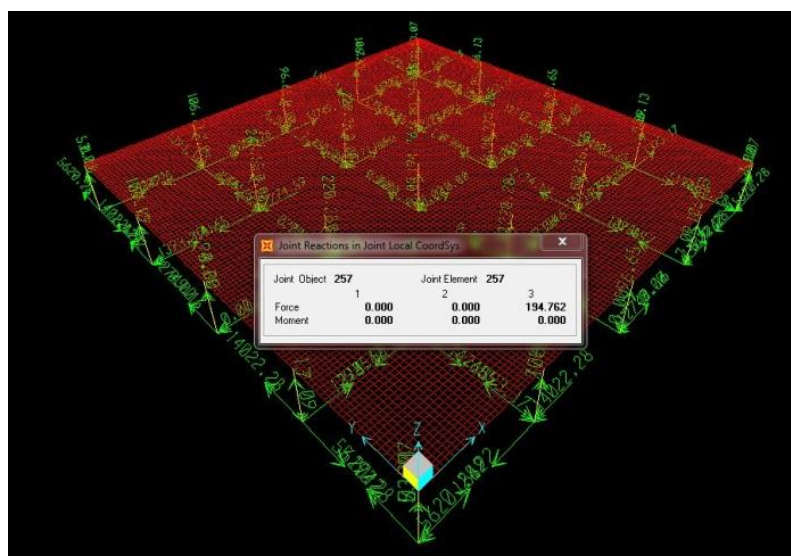

Figure 1: Reaction of voided Flat slab

\section{Deflection}

The analysis for deflection is carried out for voided slabs and solid slabs in SAP 2000 ranging from $6 \times 6 \mathrm{~m}$ to $14 \times 14 \mathrm{~m}$ having thickness $280 \mathrm{~mm}$ to $600 \mathrm{~mm}$ with spherical ball diameter $180 \mathrm{~mm}$ to $450 \mathrm{~mm}$ respectively and slabs having 4 bays in both direction. To verify the results the value of deflection is compared with numerical calculation of voided slab by considering specified width of slab as a beam. To obtain the results the modified value of Self-weight and Stiffness multiplication factor is applied for voided slabs. The results have shown that for all the cases, the deflection is almost same for voided and solid flat slabs under same loading condition at the same point and results are match with numerical calculation. To validate the results of deflection taken from SAP 2000 for voided flat slab, the numerical calculation is carry out of voided slab and the results are shown in Table -3. The Comparative results of deflection for voided and solid Flat slabs are shown in Table -4 . 
Parametric Study of R.C.C Voided and Solid Flat Plate Slab using SAP 2000

Table -3 Result for validation of Deflection

\begin{tabular}{|c|c|c|c|c|}
\hline \multirow{2}{*}{ Slab Thk (mm) } & \multirow{2}{*}{ Ball Diameter (mm) } & \multirow{2}{*}{ Span (m) } & \multicolumn{2}{|c|}{ Deflection (mm) } \\
\hline & & & Voided Slab & Numerical Calculation \\
\hline \multirow{3}{*}{280} & \multirow{3}{*}{180} & $6 \times 6$ & 2.24 & 2.22 \\
\hline & & $7 \times 7$ & 4.14 & 4.12 \\
\hline & & $8 \times 8$ & 7.08 & 7 \\
\hline \multirow{3}{*}{330} & \multirow{3}{*}{225} & $6 \times 6$ & 1.58 & 1.58 \\
\hline & & $7 \times 7$ & 2.92 & 2.92 \\
\hline & & $8 \times 8$ & 5 & 4.99 \\
\hline \multirow{2}{*}{370} & \multirow{2}{*}{270} & $8 \times 8$ & 3.97 & 3.92 \\
\hline & & $9 \times 9$ & 6.35 & 6.32 \\
\hline \multirow{2}{*}{420} & \multirow{2}{*}{315} & $9 \times 9$ & 4.95 & 4.93 \\
\hline & & $10 \times 10$ & 7.57 & 7.51 \\
\hline \multirow{2}{*}{470} & \multirow{2}{*}{360} & $10 \times 10$ & 5.97 & 5.94 \\
\hline & & $11 \times 11$ & 8.77 & 8.7 \\
\hline \multirow{2}{*}{520} & \multirow{2}{*}{405} & $11 \times 11$ & 7.18 & 7.15 \\
\hline & & $12 \times 12$ & 10.22 & 10.13 \\
\hline \multirow{2}{*}{600} & \multirow{2}{*}{450} & $13 \times 13$ & 10.43 & 10.32 \\
\hline & & $14 \times 14$ & 14.11 & 13.9 \\
\hline
\end{tabular}

Table -4 Result of Deflection for voided and solid flat slab

\begin{tabular}{|c|c|c|c|c|}
\hline \multirow{2}{*}{ Slab Thk (mm) } & \multirow{2}{*}{ Ball Diameter (mm) } & \multirow{2}{*}{ Span (m) } & \multicolumn{2}{|c|}{ Deflection $(\mathrm{mm})$} \\
\hline & & & Voided Slab & Solid Slab \\
\hline \multirow{3}{*}{280} & \multirow{3}{*}{180} & $6 \times 6$ & 2.24 & 2.32 \\
\hline & & $7 \times 7$ & 4.14 & 4.34 \\
\hline & & $8 \times 8$ & 7.08 & 7.4 \\
\hline \multirow{3}{*}{330} & \multirow{3}{*}{225} & $6 \times 6$ & 1.58 & 1.68 \\
\hline & & $7 \times 7$ & 2.92 & 3.12 \\
\hline & & $8 \times 8$ & 5 & 5.33 \\
\hline \multirow{2}{*}{370} & \multirow{2}{*}{270} & $8 \times 8$ & 3.97 & 4.24 \\
\hline & & $9 \times 9$ & 6.35 & 6.79 \\
\hline \multirow{2}{*}{420} & \multirow{2}{*}{315} & $9 \times 9$ & 4.95 & 5.27 \\
\hline & & $10 \times 10$ & 7.57 & 8.03 \\
\hline \multirow{2}{*}{470} & \multirow{2}{*}{360} & $10 \times 10$ & 5.97 & 6.41 \\
\hline & & $11 \times 11$ & 8.77 & 9.39 \\
\hline \multirow{2}{*}{520} & \multirow{2}{*}{405} & $11 \times 11$ & 7.18 & 7.67 \\
\hline & & $12 \times 12$ & 10.22 & 10.87 \\
\hline \multirow{2}{*}{600} & \multirow{2}{*}{450} & $13 \times 13$ & 10.43 & 11.24 \\
\hline & & $14 \times 14$ & 14.11 & 15.12 \\
\hline
\end{tabular}

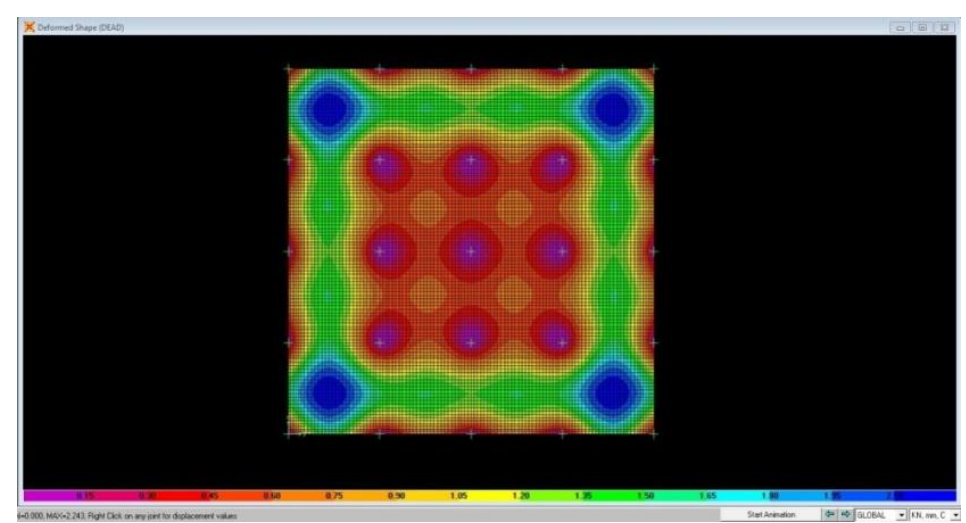

Figure 2: Deflection of Voided Flat Slab

\section{Moment}

The results for moments are also carried out same as deflection for all the cases considering only gravity loading. Here the results of moment show at the point where the maximum positive moments are occurred. From the modelling of the slabs, it revealed that for both the system voided flat plate slab and solid flat plate slab, the location of point is same where the maximum positive moment occur. The SAP 2000 results show that the maximum moments in the voided flat plat slabs are 7 to $10 \%$ less than that of the solid concrete slab under the same loading conditions. This is a consequence of the decreased dead load from the hollow spheres in place of concrete. The results of moment for voided flat plate slab and solid flat plate slab are shown in Table -5 . 
Table -5 Result of Moment for voided and solid flat slab

\begin{tabular}{|c|c|c|c|c|}
\hline \multirow{2}{*}{ Slab Thk (mm) } & \multirow{2}{*}{ Ball Diameter (mm) } & \multirow{2}{*}{ Span (m) } & \multicolumn{2}{|c|}{ Moment (KN.mm/mm) } \\
\hline & & & Voided Slab & Solid Slab \\
\hline \multirow{3}{*}{280} & \multirow{3}{*}{180} & $6 \times 6$ & 21.28 & 23.07 \\
\hline & & $7 \times 7$ & 28.8 & 31.04 \\
\hline & & $8 \times 8$ & 37.62 & 41.01 \\
\hline \multirow{3}{*}{330} & \multirow{3}{*}{225} & $6 \times 6$ & 24.48 & 27.19 \\
\hline & & $7 \times 7$ & 33.25 & 37.01 \\
\hline & & $8 \times 8$ & 43.52 & 48.34 \\
\hline \multirow{2}{*}{370} & \multirow{2}{*}{270} & $8 \times 8$ & 48.74 & 54.19 \\
\hline & & $9 \times 9$ & 61.82 & 68.59 \\
\hline \multirow{2}{*}{420} & \multirow{2}{*}{315} & $9 \times 9$ & 70.34 & 77.86 \\
\hline & & $10 \times 10$ & 87.23 & 96.13 \\
\hline \multirow{2}{*}{470} & \multirow{2}{*}{360} & $10 \times 10$ & 96.48 & 107.57 \\
\hline & & $11 \times 11$ & 117.47 & 130.16 \\
\hline \multirow{2}{*}{520} & \multirow{2}{*}{405} & $11 \times 11$ & 130.28 & 144.01 \\
\hline & & $12 \times 12$ & 155.77 & 171.38 \\
\hline \multirow{2}{*}{600} & \multirow{2}{*}{450} & $13 \times 13$ & 208.22 & 232.08 \\
\hline & & $14 \times 14$ & 242.79 & 269.16 \\
\hline
\end{tabular}

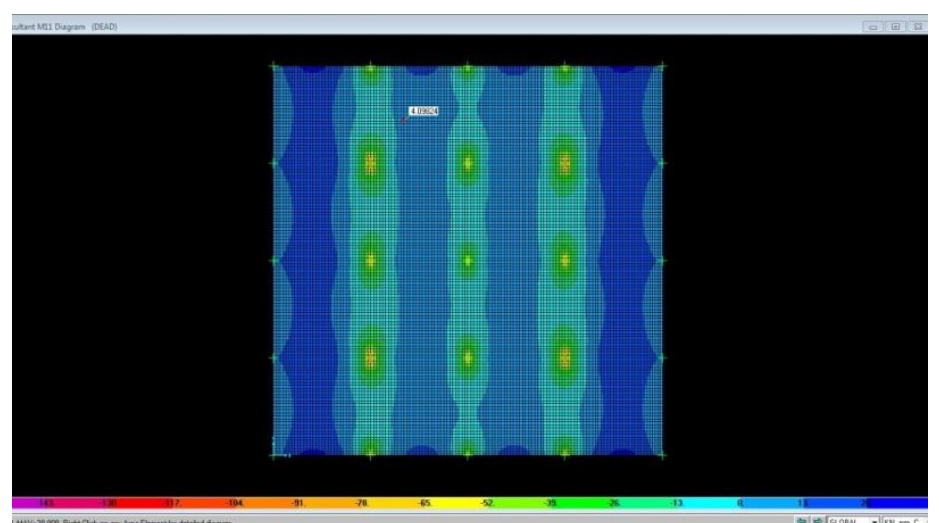

Figure 3: Moment of Voided Flat Slab

\section{Reinforcement}

In this paper, the requirement of reinforcement is derive by considering interior panel of voided and solid concrete flat plate slab, while load applied on the voided flat plate slabs are $4 \mathrm{KN} / \mathrm{m}^{2}$ Live load and 1 $\mathrm{KN} / \mathrm{m}^{2}$ floor finish load and self-weight of the slab also apply. The grade of concrete considers $25 \mathrm{~N} / \mathrm{mm}^{2}$. The calculation of reinforcement are carried out on more number of voided flat plate slabs with dimensions ranges from $6 \times 6 \mathrm{~m}$ slab to $14 \times 14 \mathrm{~m}$ slab having slab thickness $280 \mathrm{~mm}$ to $600 \mathrm{~mm}$. The result shows that, less number of reinforcement is required for voided flat slabs than that of solid flat slabs. Therefore, the self-weight of the voided slab is further reduced up to $20 \%$ of the solid flat plat slabs. The results are shown in Table -6 .

Table -6 Reinforcement required for voided and solid flat slab

\begin{tabular}{|c|c|c|c|c|c|c|c|c|c|}
\hline $\begin{array}{c}\text { Slab } \\
\text { Thickness } \\
\text { (mm) }\end{array}$ & $\begin{array}{c}\text { Ball } \\
\text { Diameter } \\
(\mathrm{mm})\end{array}$ & $\begin{array}{c}\text { Size of } \\
\text { Span (both } \\
\text { side) }(\mathrm{m})\end{array}$ & $\begin{array}{l}\text { No. of bar } \\
\text { for Voided } \\
\text { slab }\end{array}$ & $\begin{array}{l}\text { No. of bar } \\
\text { for Solid } \\
\quad \text { Slab }\end{array}$ & $\begin{array}{c}\text { Diameter } \\
\text { of bar } \\
(\mathrm{mm})\end{array}$ & $\begin{array}{l}\text { Weight } \\
\text { of each } \\
\text { bar } \\
(\mathrm{kg} / \mathrm{m})\end{array}$ & $\begin{array}{c}\text { Total } \\
\text { Weight of } \\
\text { bar for } \\
\text { void }(\mathrm{kg})\end{array}$ & $\begin{array}{c}\text { Total } \\
\text { Weight of } \\
\text { bar for } \\
\text { solid }(\mathrm{kg})\end{array}$ & $\%$ Weight \\
\hline \multirow{3}{*}{280} & \multirow{3}{*}{180} & 6 & 68 & 79 & 10 & 0.617 & 251.74 & 292.46 & 13.92 \\
\hline & & 7 & 78 & 90 & 12 & 0.888 & 484.85 & 559.44 & 13.33 \\
\hline & & 8 & 120 & 140 & 12 & 0.888 & 852.48 & 994.56 & 14.29 \\
\hline \multirow{3}{*}{330} & \multirow{3}{*}{225} & 6 & 59 & 70 & 10 & 0.617 & 218.42 & 259.14 & 15.71 \\
\hline & & 7 & 66 & 79 & 12 & 0.888 & 410.26 & 491.06 & 16.46 \\
\hline & & 8 & 102 & 120 & 12 & 0.888 & 724.61 & 852.48 & 15.00 \\
\hline \multirow{2}{*}{370} & \multirow{2}{*}{270} & 8 & 90 & 110 & 12 & 0.888 & 639.36 & 781.44 & 18.18 \\
\hline & & 9 & 74 & 91 & 16 & 1.58 & 1052.28 & 1294.02 & 18.68 \\
\hline \multirow{2}{*}{420} & \multirow{2}{*}{315} & 9 & 68 & 84 & 16 & 1.58 & 966.96 & 1194.48 & 19.05 \\
\hline & & 10 & 94 & 118 & 16 & 1.58 & 1485.20 & 1864.40 & 20.34 \\
\hline \multirow{2}{*}{470} & \multirow{2}{*}{360} & 10 & 86 & 108 & 16 & 1.58 & 1358.80 & 1706.40 & 20.37 \\
\hline & & 11 & 118 & 148 & 16 & 1.58 & 2050.84 & 2572.24 & 20.27 \\
\hline \multirow{2}{*}{520} & \multirow{2}{*}{405} & 11 & 110 & 140 & 16 & 1.58 & 1911.80 & 2433.20 & 21.43 \\
\hline & & 12 & 94 & 120 & 20 & 2.47 & 2786.16 & 3556.80 & 21.67 \\
\hline \multirow{2}{*}{600} & \multirow{2}{*}{450} & 13 & 116 & 150 & 20 & 2.47 & 3724.76 & 4816.50 & 22.67 \\
\hline & & 14 & 150 & 189 & 20 & 2.47 & 5187.00 & 6535.62 & 20.63 \\
\hline
\end{tabular}




\section{Conclusions}

From the results it may be conclude that, the methodology adopted for the modelling of the voided flat plate slab, that is by substitution of stiffness multiplication factor and modified self-weight of the voided flat slab is acceptable because, the results of reaction is same for reinforced concrete voided and solid flat plate slab systems. For all the cases of the voided flat slab, the results for deflection is almost same as compared to that of solid flat slabs under same loading and at the same point. Therefore, by applying the stiffness multiplication factor, we can obtain the deflection of the voided flat slab same as solid flat slab. Same as deflection, results of moment is also observed for various cases of voided and solid flat plat slabs. From the results, it may conclude that, due to reduced self-weight of the voided flat plate slab, the moment of the slabs is reduced from 7 to $10 \%$ of the solid flat slab at the same point under same loading condition. As, the moment occur per unit width of the voided slab is less than that of solid flat slab; the reinforcement required for the voided flat slab is also reduced. Due to that, the self-weight of the voided slab further reduced up to $20 \%$ of the solid flat slab. Therefore, from this study we can conclude that, the voided flat plate slab can designed by using traditional design principles of solid flat slab by substitution of stiffness multiplication factor and modified self-weight of the voided flat slab.

\section{References}

[1]. C. C. Marais, J. M. Robberts and B. W. J. van Rensburg, "Spherical void formers in concrete slabs", Journal of the South African Institution of Civil Engineering, Vol 52 No 2, pp. 2 - 11, October 2010.

[2]. J. H. Chung \& J. H. Park, H. K. Choi, S. C. LEE and C. S. CHOI, "An analytical study on the impact of hollow spheres in bi-axial hollow slabs", Fracture Mechanics of Concrete and Concrete Structure, pp. 1729 - 1736, 2010.

[3]. Mike Mota, "Voided slabs then and now", Concrete Industry Board Bulletin, Summer 2010.

[4]. BubbleDeck Design Guide for compliance with BCA using AS3600 and EC2 31, October 2008.Unpublished manuscript.

[5]. CBD-MS \& CRO, Cobiax Technology Handbook, Switzerland: Cobiax Technologies AG Zug.

[6]. Amer M. Ibrahim, Nazar K. Ali, Wissam D. Salman, "Flexural Capacities of Two-way Reinforced Concrete BubbleDeck slabs of Plastic Spherical Voids", Diyala journals of Engineering Sciences, Vol. 06, No. 02, pp. $9-20$

[7]. L.V. Hai, V.D. Hung, T.M. Thi, T. Nguyen- Thoi, N.T. Phuoc, "The Experimental analysis of BubbleDeck Slabs Using Modified Elliptical Balls", 2013.

[8]. Joe Nasvik, "placing concrete around plastic voids increases efficiency and reduces costs", Concrete Construction, December 2012.

[9]. C. C. Marais, "Design adjustment factors and the economical application of concrete flat slabs with internal spherical voids in south Africa", M.E Dissertation, University of Pretoria. 